\title{
Effects of Metformin on Thyroid Function in Patients of Subclinical Hypothyroidism
}

\author{
Rajesh Rajput ${ }^{\mathrm{a}, \mathrm{d}}$, Madhu Saini ${ }^{\mathrm{a}}$, Meena Rajput ${ }^{\mathrm{b}}$, Vijay Shankar ${ }^{\mathrm{c}}$
}

\begin{abstract}
Background: To study the effect of metformin on thyroid function test (TFT) in patients of subclinical hypothyroidism ( $\mathrm{SCH})$.

Methods: A total of 30 patients of SCH with TSH between 5 - 10 $\mathrm{mIU} / \mathrm{L}$ were given 2,000 mg/day of metformin for 12 weeks. Patients were divided into two groups based on presence or absence of thyroid peroxidase antibody (TPO). Baseline anthropometric characteristics, fT3, fT4, TSH, serum insulin, HOMA-IR and quality of life were assessed at baseline and at 12 weeks.
\end{abstract}

Results: A total of 23 patients $(76.7 \%)$ who were TPO antibody negative (group 1) showed statistically significant decrease in TSH concentration at 12 weeks with no significant change in fT 3 and fT4 in contrast to 7 patients $(23.3 \%)$ who were TPO antibody positive (group 2). Patients in group 1 were significantly more obese, had higher serum insulin and HOMA-IR as compared to group 2. Body weight, waist circumference, BMI and percentage body fat decreases significantly in both the groups at 12 weeks as compared to baseline but on intergroup comparison this decrease was not significant statistically $(\mathrm{P}=0.46)$. The HOMA-IR of group 1 was significantly higher than that of group 2 at baseline $(P \leq 0.02)$. Serum insulin and HOMA-IR decreased significantly in both the groups but again on intergroup comparison, no significant difference was observed. A positive correlation between serum TSH and serum insulin level and HOMA-IR level $(\mathrm{r}=0.608, \mathrm{P} \leq 0.01$ and $\mathrm{r}=0.592, \mathrm{P} \leq 0.01$ respectively) was observed in group 1 .

Conclusion: Metformin suppresses serum TSH levels without af-

\footnotetext{
Manuscript accepted for publication August 28, 2013

${ }^{a}$ Department of Medicine VI and Endocrinology, Pt. B.D.S. PGIMS, Rohtak, Haryana, India

${ }^{\mathrm{b}}$ Department of Community Medicine, Pt. B.D.S. PGIMS, Rohtak, Haryana, India

${ }^{\mathrm{c}}$ Department of Biochemistry, Pt. B.D.S. PGIMS, Rohtak, Haryana, India

${ }^{\mathrm{d}}$ Corresponding author: Rajesh Rajput, Department of Medicine VI and Endocrinology, PGIMS, Rohtak-124001, Haryana, India.

Email: drrajeshrajput@outlook.com
}

doi: http://dx.doi.org/10.4021/jem188w fecting fT3 and fT4 levels in SCH without any evidence of autoimmune thyroiditis.

Keywords: Subclinical hypothyroidism; Metformin; Thyroid function

\section{Introduction}

Subclinical hypothyroidism ( $\mathrm{SCH})$ is defined as serum thyrotropin (TSH) concentration above statistically defined upper limit of normal reference range with normal serum free levothyroxine (fT4) concentration [1]. The prevalence of $\mathrm{SCH}$ increases with age, is higher in women but after sixty years of age prevalence in men approaches that of women with a combined prevalence of $10 \%[1,2]$. Most clinicians agree that individuals with TSH level higher than $10 \mathrm{mIU} / \mathrm{L}$ should be treated with levothyroxine (LT4) but there is uncertainty regarding usefulness of treating those with TSH levels between $5-10 \mathrm{mIU} / \mathrm{L}[3,4]$. Also at the same time failure to decrease LT4 dosage in those developing subnormal TSH level while on treatment puts these patients to undesirable side effects of LT4 on bone density and cardiac function $[5,6]$.

Metformin is a biguanide derivative oral drug used for treatment of T2DM and is commonly regarded as safe drug with no clinically relevant side effect and drug interaction with exception of folate and vitamin B12 [7]. In recent years few studies have shown TSH suppressive effect of metformin with no effect on fT4 levels [8,9]. Vigersky et al [8] observed that use of metformin for a duration varying from 2 - 8 months induced reversible suppression of TSH without a change in fT4 or fT3 levels, or clinical signs of hyperthyroidism in a patient of nonalcoholic steatohepatitis who was on LT4 after radioactive iodine treatment for graves' disease and three additional hypothyroid patients (two post surgical and one with hashimoto's disease) who developed TSH suppression when they were placed on metformin for treatment of diabetes mellitus. In contrast oleandri et al [9] found no difference in thyroid function test among 28 patients who were treated for obesity with metformin. Thus till today no 
Table 1. Baseline Characteristics of Group 1 and Group 2

\begin{tabular}{llll}
\hline Baseline Characteristics & Group 1 $(\mathbf{n}=\mathbf{2 3})$ & Group 2 $(\mathbf{n}=\mathbf{7})$ & P value \\
\hline Age (years) & $36.70 \pm 7.32$ & $39 \pm 13.68$ & 0.09 \\
Weight $(\mathrm{kg})$ & $70.96 \pm 9.22$ & $62.43 \pm 7.79$ & 0.02 \\
BMI $\left(\mathrm{kg} / \mathrm{m}^{2}\right)$ & $29.39 \pm 4.56$ & $24.29 \pm 2.81$ & 0.004 \\
Waist Circumference $(\mathrm{cm})$ & $91.43 \pm 8.58$ & $82.14 \pm 2.41$ & 0.001 \\
Body fat $(\%)$ & $36.38 \pm 4.39$ & $31.86 \pm 5.70$ & 0.02 \\
fT3 $(2.4-4.2 \mathrm{pg} / \mathrm{mL})$ & $2.83 \pm 0.65$ & $3.14 \pm 0.38$ & 0.21 \\
fT4 $(0.8-1.7 \mathrm{ng} / \mathrm{dL})$ & $1.04 \pm 0.21$ & $1.00 \pm 0.14$ & 0.3 \\
TSH $(0.34-4.25 \mathrm{mIU} / \mathrm{L})$ & $7.39 \pm 1.37$ & $7.29 \pm 1.38$ & 0.83 \\
Anti TPO Ab $(<60 \mathrm{IU} / \mathrm{mL})$ & $45.17 \pm 19.55$ & $2186.29 \pm 2110.00$ & $<0.001$ \\
S. Insulin $(\mathrm{mIU} / \mathrm{L})$ & $15.30 \pm 3.62$ & $8.29 \pm 3.82$ & $<0.01$ \\
HOMA-IR & $3.20 \pm 0.84$ & $2.00 \pm 1.00$ & 0.02 \\
TG (mg/dL) & $135.91 \pm 36.34$ & $134.00 \pm 40.17$ & 0.71 \\
Cholesterol (mg/dL) & $174.17 \pm 18.55$ & $180.86 \pm 27.55$ & 0.76 \\
HDL (mg/dL) & $42.04 \pm 4.56$ & $42.71 \pm 2.93$ & 0.43 \\
LDL (mg/dL) & $109.22 \pm 17.89$ & $114.71 \pm 24.63$ & 0.69 \\
VLDL (mg/dL) & $22.87 \pm 4.90$ & $23.57 \pm 8.92$ & 0.91 \\
\hline
\end{tabular}

definite conclusion has been drawn behind thyrotropin lowering effect of metformin and the likely mechanism remains unclear. Due to lack of conclusive data regarding effect of metformin in patients of mild SCH with TSH level $5-10$ $\mathrm{mIU} / \mathrm{L}$, the present study was planned to see the effects of metformin administration on thyroid function test in patients with mild SCH.

\section{Material and Methods}

The study was conducted in 30 consecutive newly diagnosed drug naive SCH subjects with TSH level between $5-10$ $\mathrm{mIU} / \mathrm{L}$ attending "Endocrinology Clinic" at PGIMS Rohtak. A written consent was taken from all patients and the institutional review board at University of Health Sciences approved the study protocol. The patients with overt hypothyroidism, those taking levothyroxine and/or anti thyroid drugs, patients suffering from any chronic diseases including T2DM, pregnant and post-partum women were excluded from the study. None of the patients had gastro-intestinal disease. The study was carried for a time period of 12 weeks. Anthropometric parameters, thyroid function tests, plasma glucose, serum insulin level, serum lipid levels and quality of life parameters were assessed at baseline (before start of treatment) and at 12 weeks. Percentage body fat (BF) was calculated by impedance plethysmography (bioelectrical impedance meter Omron BF 302). Percentage body fat $>25 \%$ in men and $>30 \%$ in women was used as criteria to define overweight in healthy subjects $[10,11]$. Thyroid peroxidase antibody (TPO) levels were assessed in all the patients to assess etiology of SCH. fT3 (normal range: 2.4 - $4.2 \mathrm{pg} / \mathrm{mL}$ ) and fT4 (normal range: $0.89-1.76 \mathrm{ng} / \mathrm{dL}$ ) were assessed by chemiluminescent method using analyzer and kits of Siemens (ADIVA Centaur CP). TSH (normal range: 0.34 - 4.25 $\mathrm{mIU} / \mathrm{L}$ ) was done by immunometric assay (PC RIA MAS by Startek) by Turbo TSH using IRMA kit. Lipid profile was assessed by Konelab 30i using analyzing kits by Randox. Serum insulin was measured by Elisa method and insulin resistance was calculated by HOMA-IR (Homeostatic model assessment for insulin resistance) [12]. Quality of life was assessed by RAND 36 which measured health according to eight subscales which are: physical functioning, role limitation due to physical health, role limitation due to emotional problems, energy/fatigue, emotional wellbeing, social functioning, pain and general health. The scale score ranged from 0 to 100 for every subscale, with a higher outcome meaning a better health status [13].

The therapeutic efficacy of metformin across various dosage regimens were studied by Garber et al [14] and found 
Table 2. Showing Anthropometric Parameters in Group 1 and 2 at Baseline and at 12 Weeks

\begin{tabular}{|c|c|c|c|c|}
\hline \multirow{2}{*}{$\begin{array}{l}\text { Anthropometric } \\
\text { parameters }\end{array}$} & \multicolumn{2}{|c|}{ Group $1(n=23)$} & \multicolumn{2}{|c|}{ Group $2(n=7)$} \\
\hline & Baseline & $12 \mathrm{WKS}$ & Baseline & $12 \mathrm{WKS}$ \\
\hline Body wt (kg) & $70.96 \pm 9.22$ & $\begin{array}{l}69.17 \pm 8.77 \\
(\mathrm{P}<0.01)\end{array}$ & $62.43 \pm 7.79$ & $\begin{array}{l}62.14 \pm 7.54 \\
(P=0.03)\end{array}$ \\
\hline BMI $\left(\mathrm{kg} / \mathrm{m}^{2}\right)$ & $29.44 \pm 4.55$ & $\begin{array}{l}28.65 \pm 4.44 \\
(\mathrm{P}<0.01)\end{array}$ & $24.27 \pm 2.73$ & $\begin{array}{l}24.17 \pm 2.65 \\
(P=0.03)\end{array}$ \\
\hline $\mathrm{WC}(\mathrm{cm})$ & $91.43 \pm 8.58$ & $\begin{array}{l}90.17 \pm 8.36 \\
(\mathrm{P}<0.01)\end{array}$ & $82.14 \pm 2.41$ & $\begin{array}{l}81.35 \pm 2.37 \\
(P=0.02)\end{array}$ \\
\hline $\mathrm{BF}(\%)$ & $36.43 \pm 4.38$ & $\begin{array}{l}35.17 \pm 4.42 \\
(P=0.01)\end{array}$ & $31.80 \pm 5.42$ & $\begin{array}{l}31.30 \pm 5.24 \\
(P=0.001)\end{array}$ \\
\hline
\end{tabular}

that the efficacy of metformin plateau after $2,000 \mathrm{mg}$ /day and therefore a dose of $200 \mathrm{mg} /$ day of metformin was chosen for this study. All patients were given metformin $500 \mathrm{mg}$ twice a day for period of one week and then dose was escalated to $1,000 \mathrm{mg}$ twice a day for remaining eleven weeks. Patients failing to tolerate total dose of $2,000 \mathrm{mg} /$ day due to gastro-intestinal side effects were excluded from the study. Based on results of TPO antibody patients were divided into two groups and appropriate statistical methods were used for analysis of the data.

\section{Results}

Out of thirty patients 2 were male and 28 were female with mean age of $33.5 \pm 9.39$ years. Twenty-three patients with TPO antibody in normal range form group one and seven patients with elevated TPO antibody form group two. The baseline characteristics of both the groups are shown in Table 1. There was no statistical significant difference in TSH between the two groups at baseline $(\mathrm{P}=0.83)$. Patients in group 1 were significantly more obese, had higher serum insulin and HOMA-IR as compared to group 2. Significant reduction in serum TSH was seen in group 1 at the end of 12 weeks $(\mathrm{P}<0.001)$ with no effects on fT4 and fT3 levels while in group 2 increase in serum TSH was seen at the end of 12 weeks which was statistically significant $(\mathrm{P}<0.01)$. In group 1 out of 23 patients who showed reduction in TSH concentration at 12 weeks, only 9 patients $(39.13 \%)$ attained euthyroidism as defined by TSH level less than $4.25 \mathrm{mIU} / \mathrm{L}$. Body weight, waist circumference, BMI and percentage body fat decreases significantly in both the groups at 12 weeks as compared to baseline but on intergroup comparison this decrease was not significant statistically $(P=0.46)$. The HOMA-IR of group 1 was significantly higher than that of group 2 at baseline $(\mathrm{P} \leq 0.02)$. Serum insulin and HOMA-IR decreased significantly in both the groups but again on intergroup comparison, no significant difference was observed. Table 2 and 3 shows comparison of anthropometric parameters and various biochemical parameters between two groups at baseline and at 12 weeks. A positive correlation between serum TSH and serum insulin level and HOMA-IR level ( $\mathrm{r}$ $=0.608, \mathrm{P} \leq 0.01$ and $\mathrm{r}=0.592, \mathrm{P} \leq 0.01$ respectively) was observed in group 1. None of the patient in either group develop clinical or biochemical hypoglycemia during the study period. On quality of life assessment (QOL) statistically significant improvement in scores of energy/fatigue was seen in both the groups at 12 weeks while significant improvement in scores of physical functioning, role limitation due to physical health, emotional well being and social functioning, pain and general health was seen in group 1 at 12 weeks.

\section{Discussion}

Subclinical hypothyroidism has been detected with increasing frequency in recent years and is causing major controversies concerning management and treatment. Treatment of patients with a serum TSH level between 5 and $10 \mathrm{mIU} / \mathrm{L}$, remains controversial $[3,4]$. The strongest arguments for levothyroxine therapy are the high risk of progression to overt hypothyroidism, the possible improvement of quality of life, and the possibility that $\mathrm{SCH}$ is a cardiovascular risk factor but the potential risks of therapy include development of subclinical hyperthyroidism, which may occur in $14 \%$ to $21 \%$ of individuals treated with levothyroxine [3-6]. 
Table 3. Showing Biochemical Parameters in Group 1 and 2 at Baseline and at 12 Weeks

\begin{tabular}{|c|c|c|c|c|}
\hline \multirow{2}{*}{ Biochemical parameter } & \multicolumn{2}{|c|}{ Group $1(n=23)$} & \multicolumn{2}{|c|}{ Group $2(n=7)$} \\
\hline & Baseline & $12 \mathrm{WKS}$ & Baseline & $12 \mathrm{WKS}$ \\
\hline fT3 $(\mathrm{pg} / \mathrm{mL})$ & $2.76 \pm 0.53$ & $\begin{array}{l}2.79 \pm 0.55 \\
(P=0.27)\end{array}$ & $3.18 \pm 0.36$ & $\begin{array}{l}2.73 \pm 0.31 \\
(P=0.02)\end{array}$ \\
\hline fT4 (ng/dL) & $1.11 \pm 0.19$ & $\begin{array}{l}1.10 \pm 0.28 \\
(P=0.75)\end{array}$ & $1.03 \pm 0.18$ & $\begin{array}{l}0.88 \pm 0.12 \\
(\mathrm{P}=0.02)\end{array}$ \\
\hline TSH (mIU/L) & $7.33 \pm 1.37$ & $\begin{array}{l}5.00 \pm 1.38 \\
(\mathrm{P}<0.01)\end{array}$ & $7.05 \pm 1.33$ & $\begin{array}{l}8.55 \pm 1.08 \\
(P=0.003)\end{array}$ \\
\hline $\mathrm{FPG}(\mathrm{mg} / \mathrm{dL})$ & $84.96 \pm 10.59$ & $\begin{array}{l}80.74 \pm 6.95 \\
(P=0.07)\end{array}$ & $81.43 \pm 3.21$ & $\begin{array}{l}77.14 \pm 4.98 \\
(\mathrm{P}=0.07)\end{array}$ \\
\hline S.INSULIN (mU/L) & $15.30 \pm 3.63$ & $\begin{array}{l}8.28 \pm 2.76 \\
(P<0.01)\end{array}$ & $8.30 \pm 3.82$ & $\begin{array}{l}5.66 \pm 2.51 \\
(P=0.004)\end{array}$ \\
\hline HOMA-IR & $3.20 \pm 0.84$ & $\begin{array}{l}1.65 \pm 0.57 \\
(P<0.01)\end{array}$ & $1.95 \pm 0.86$ & $\begin{array}{l}1.29 \pm 0.66 \\
(P=0.001)\end{array}$ \\
\hline $\mathrm{TG}(\mathrm{mg} / \mathrm{dL})$ & $135.93 \pm 36.36$ & $\begin{array}{l}127.04 \pm 32.63 \\
(P<0.01)\end{array}$ & $133.99 \pm 40.02$ & $\begin{array}{l}127.54 \pm 42.74 \\
(\mathrm{P}=0.02)\end{array}$ \\
\hline CHOLESTEROL (mg/dL) & $174.17 \pm 18.55$ & $\begin{array}{l}168.78 \pm 16.58 \\
(P<0.01)\end{array}$ & $180.93 \pm 27.62$ & $\begin{array}{l}174.06 \pm 17.0 \\
(P=0.16)\end{array}$ \\
\hline $\operatorname{HDL}(\mathrm{mg} / \mathrm{dL})$ & $42.04 \pm 4.56$ & $\begin{array}{l}43.26 \pm 3.57 \\
(P=0.002)\end{array}$ & $42.71 \pm 2.96$ & $\begin{array}{l}43.71 \pm 2.98 \\
(P=0.03)\end{array}$ \\
\hline LDL (mg/dL) & $109.22 \pm 17.89$ & $\begin{array}{l}103.17 \pm 16.28 \\
(\mathrm{P}<0.01)\end{array}$ & $114.67 \pm 24.72$ & $\begin{array}{l}107.69 \pm 19.23 \\
(\mathrm{P}=0.04)\end{array}$ \\
\hline VLDL (mg/dL) & $22.87 \pm 4.89$ & $\begin{array}{l}23.09 \pm 5.5 \\
(\mathrm{P}=0.75)\end{array}$ & $23.54 \pm 8.83$ & $\begin{array}{l}22.66 \pm 6.36 \\
(P=0.71)\end{array}$ \\
\hline
\end{tabular}

Various studies have shown the effects of metformin on thyroid profile of the hypothyroid/subclinical hypothyroid patients stating a TSH lowering effect of the drug [15-17]. However no definite conclusion has been derived till date behind these findings and the mechanism still remain unclear.

In the present study patients of subclinical hypothyroidism who are more obese, had higher degree of insulin resistance and were TPO antibody negative responded favorably to metformin therapy at 12 weeks as compared to individuals of $\mathrm{SCH}$ with underlying autoimmune etiology as suggested by presence of TPO antibody. Similar observation were made by Rotondi et al [15] who showed that autoimmune hypothyroidism is more prevalent in patients with lower degrees of weight excess, whereas a high serum level of TSH, not indicative of thyroid failure, would pre- dominate in morbidly obese patients suggesting that obese patients often present with elevated serum level of TSH. A study done in rats demonstrated that animals fed a high fat diet for 8 weeks display an increase in their serum levels of TSH, which was not accompanied by changes in serum fT3 and fT4 [16]. Our findings that TSH lowering effect is observed only in individuals who were TPO antibody negative are in contrast with observation made by Capelli et al [17] who showed that significant reduction in TSH level was seen in those patients on metformin who had a baseline TSH higher than $2.5 \mathrm{mIU} / 1$ independent of presence or absence of TPO antibodies. But the study done by capelli et al [17] was a retrospective study on euthyroid diabetic patients while the present study was a prospective one involving non-diabetic subjects. Also none of author had studies anthropometric indices and insulin resistance in patients of $\mathrm{SCH}$ subjects who 
were given metformin therapy, which has been observed to decrease significantly with treatment in the present study. Similar observations were made by Taghavi et al [18] who studied the effect of metformin administration on thyroid function in overweight women with polycystic ovarian syndrome. They selected twenty-seven overweight women with PCOS and subclinical hypothyroidism. Fifteen patients were treated with metformin $1,500 \mathrm{mg}$ /day for 6 months and 12 patients with placebo. A significant decrease in TSH levels was observed in group given metformin treatment after 6 months as compared to group given placebo treatment. No significant change in free T3 and free T4 was observed through the study in any group. They concluded that in obese PCOS patients with subclinical hypothyroidism, metformin results in a significant fall and sometimes normalization of TSH, without causing any reciprocal changes in other thyroid function parameters. Although TSH decreased statistically in all 23 obese patients in group 1 in the present study, only $9(39.13 \%)$ were able to achieve euthyroidism at 12 weeks of metformin therapy, suggesting that period of more than 3 months is required to observe this TSH lowering effect of metformin.

The various suggested mechanism of action responsible for this TSH lowering effect of metformin include an increase in number or sensitivity of thyroid receptors, an increase in dopaminergic tone, and activation of TSH receptors. Cappelli et al [17] hypothesized that metformin may enhance the inhibitory modulation of thyroid hormones on central TSH secretion. Such an effect would not modify circulating FT3 or TSH levels when the closed loop control system is normally functioning, but may well explain the reduction of circulating TSH levels observed in subjects with altered thyroid hypophyseal feedback. Another explanatory hypothesis could be that metformin ameliorates the thyroid function reserve in those patients with hypothyroidism both treated and untreated. They concluded that metformin administration in diabetic patients with hypothyroidism, both with L-T4 therapy and untreated, is associated with a significant reduction in the serum levels of TSH, with no change in FT4. No effect is detectable in patients with an intact pituitary thyroid axis. However, these hypotheses would require that metformin be able to cross the blood brain barrier but since metformin is a low molecular mass water-soluble molecule (168 Da), its penetration across blood brain barrier has not been studied. Also, if metformin produced subtle increases in the absorption of L-T4 from the gastrointestinal tract, then suppression of serum TSH might be predicted. In the present study as well in other studies the reduction in TSH level is not associated with changes in fT4 and fT3 levels suggesting that increase in LT-4 absorption is unlikely mechanism for this TSH lowering effect of metformin. In the present study we also observed a positive correlation between serum TSH and serum insulin level and HOMA-IR level $(\mathrm{r}=0.608, \mathrm{P} \leq 0.01$ and $r=0.592, \mathrm{P} \leq 0.01$ respectively) suggesting that reduction in insulin resistance secondary to use of metformin might be causing change in serum levels of insulin and adipocyte cytokine like leptin, which are known to cross blood brain barrier and might be responsible for TSH lowering of metformin. Sayed et al [10] in their study found that there was a positive correlation between serum TSH and fasting serum insulin levels. It is known that there is a complex interaction between thyroid hormones and adipose tissue where TSH and thyroid hormone may participate in adipocyte differentiation and lipolysis regulation whereas various adipocyte cytokines may interact with hypothalamic-pituitary-thyroid axis $[20,21]$. In this complex system of hypothalamic regulation, factor most favored by various authors for causing elevation of TSH is activation of hypothalamic centers by leptin released from adipocytes in fat tissue [22]. It is anticipated that with decrease in insulin resistance secondary to loss of body weight there will be decrease in serum insulin and leptin level, which will result in reduction of TSH level, and the same has been observed in the present study. However in present study apart from serum insulin levels that are found to be positively correlated with TSH levels we have not measured leptin levels and this needs to be studied and proved in future studies.

To conclude with the present study shows that metformin suppresses serum TSH levels without affecting fT3 and fT4 levels in individuals without any evidence of autoimmune thyroiditis as suggested by negative TPO antibody by improving insulin sensitivity in contrast to patients of $\mathrm{SCH}$ with underlying evidence of autoimmunity and such patients needs not to be treated with thyroid hormone unless there are other signs of thyroid disease. However to substantiate the results of present study and to explore the potential mechanism for this observed effect, further studies with a large sample size and longer duration of follow-up are needed.

\section{References}

1. Cooper DS. Clinical practice. Subclinical hypothyroidism. N Engl J Med. 2001;345(4):260-265.

2. Hollowell JG, Staehling NW, Flanders WD, Hannon WH, Gunter EW, Spencer CA, Braverman LE. Serum TSH, T(4), and thyroid antibodies in the United States population (1988 to 1994): National Health and Nutrition Examination Survey (NHANES III). J Clin Endocrinol Metab. 2002;87(2):489-499.

3. Nystrom E, Caidahl K, Fager G, Wikkelso C, Lundberg PA, Lindstedt G. A double-blind cross-over 12-month study of L-thyroxine treatment of women with 'subclinical' hypothyroidism. Clin Endocrinol (Oxf). 1988;29(1):63-75.

4. Villar HC, Saconato H, Valente O, Atallah AN. Thyroid hormone replacement for subclinical hypothyroidism. Cochrane Database Syst Rev. 20073):CD003419. 
5. Sawin CT, Geller A, Wolf PA, Belanger AJ, Baker E, Bacharach P, Wilson PW, et al. Low serum thyrotropin concentrations as a risk factor for atrial fibrillation in older persons. N Engl J Med. 1994;331(19):1249-1252.

6. Uzzan B, Campos J, Cucherat M, Nony P, Boissel JP, Perret GY. Effects on bone mass of long term treatment with thyroid hormones: a meta-analysis. J Clin Endocrinol Metab. 1996;81(12):4278-4289.

7. Bailey CJ, Day C. Metformin: its botanical background. Pract Diab Int. 2004;21:115-117.

8. Vigersky RA, Filmore-Nassar A, Glass AR. Thyrotropin suppression by metformin. J Clin Endocrinol Metab. 2006;91(1):225-227.

9. Oleandri SE, Maccario M, Rossetto R, Procopio M, Grottoli S, Avogadri E, Gauna C, et al. Three-month treatment with metformin or dexfenfluramine does not modify the effects of diet on anthropometric and endocrine-metabolic parameters in abdominal obesity. J Endocrinol Invest. 1999;22(2):134-140.

10. Pollock ML, Wilmore JH. Exercise in health and diseases. Philadelphia,PA: WB Saunders, 1990.

11. Hortobagyi T, Israel RC, O’ Brien KF. Sensitivity and specificity of quetlet index to assess obesity in men and women. Eu J Clin Nutr. 1994;48:769-775.

12. Matthews DR, Hosker JP, Rudenski AS, Naylor BA, Treacher DF, Turner RC. Homeostasis model assessment: insulin resistance and beta-cell function from fasting plasma glucose and insulin concentrations in man. Diabetologia. 1985;28(7):412-419.

13. Stewart AL, Shebourne C, Hays RD. Summary and discussion of MOS measures. In: Stewart AL, eds. Measuring functioning and wellbeing: the medical outcome study approach. Durham NC: Duke University Press; 1992:345-371.
14. Garber AJ, Duncan TG, Goodman AM, Mills DJ, Rohlf JL. Efficacy of metformin in type II diabetes: results of a double-blind, placebo-controlled, dose-response trial. Am J Med. 1997;103(6):491-497.

15. Rotondi M, Magri F, Chiovato L. Thyroid and obesity: not a one-way interaction. J Clin Endocrinol Metab. 2011;96(2):344-346.

16. Araujo RL, Andrade BM, Padron AS, Gaidhu MP, Perry RL, Carvalho DP, Ceddia RB. High-fat diet increases thyrotropin and oxygen consumption without altering circulating 3,5,3'-triiodothyronine (T3) and thyroxine in rats: the role of iodothyronine deiodinases, reverse T3 production, and whole-body fat oxidation. Endocrinology. 2010;151(7):3460-3469.

17. Cappelli C, Rotondi M, Pirola I, Agosti B, Gandossi E, Valentini U, De Martino E, et al. TSH-lowering effect of metformin in type 2 diabetic patients: differences between euthyroid, untreated hypothyroid, and euthyroid on L-T4 therapy patients. Diabetes Care. 2009;32(9):1589-1590.

18. Morteza Taghavi S, Rokni H, Fatemi S. Metformin decreases thyrotropin in overweight women with polycystic ovarian syndrome and hypothyroidism. Diab Vasc Dis Res. 2011;8(1):47-48.

19. Sayed AL A, Nadia AL A, Abbas Yosuf BO, Alfadhli EA. Subclinical hypothyroidism is associated with early insulin resistance in Kuwaiti women. Endocrine J 2006; 53:653-657.

20. Obregon MJ. Thyroid hormone and adipocyte differentiation. Thyroid. 2008;18(2):185-195.

21. Feldt-Rasmussen U. Thyroid and leptin. Thyroid. 2007; 17(5):413-419.

22. Biondi B. Thyroid and obesity: an intriguing relationship. J Clin Endocrinol Metab. 2010;95(8):3614-3617. 